\title{
CARACTERIZAÇÃO DOS ÓLEOS DAS SEMENTES DE LIMÃO ROSA (Citrus limonia Osbeck) E LIMÃO SICILIANO (Citrus limon), UM RESÍDUO AGROINDUSTRIAL ${ }^{1}$
}

\author{
Seme Youssef REDA ${ }^{2}$, Elenise Sauer LEAL ${ }^{3}$, Eduardo Augusto Caldas BATISTA ${ }^{4}$, \\ Ana Cláudia BARANA ${ }^{4}$, Egon SCHNITZEL ${ }^{5}$, Paulo Irajara Borba CARNEIRO ${ }^{5 *}$
}

\begin{abstract}
RESUMO
A finalidade deste estudo foi caracterizar os óleos extraídos das sementes de limão rosa e limão siciliano, como aproveitamento de resíduos industriais. Foram determinados os índices de iodo, ácidos graxos livres (AGL,\% em ácido oléico) e teor de peróxidos. Foram realizadas análises termoanalíticas (termogravimetria, TG; termogravimetria diferencial, DTG e calorimetria diferencial exploratória, DSC); espectroscópicas (infravermelho e ultravioleta) e cromatográficas (cromatografia gasosa). Foram identificados no óleo das sementes de limão rosa os seguintes ácidos graxos na forma de ésteres metílicos: caprílico (0,90\%), palmítico (21,40\%), esteárico $(2,60 \%)$, oléico $(21,20 \%)$, linoléico $(43,00 \%)$, linolênico $(7,60 \%)$ e araquídico $(0,20 \%)$ e no óleo das sementes de limão siciliano: caprílico ( $1,00 \%)$, mirístico $(0,10 \%)$, palmítico ( $19,60 \%)$, esteárico $(3,00 \%)$, oléico (28,60\%), linoléico (34,40\%), linolênico $(10,00 \%)$ e araquídico $(0,20 \%)$. Os resultados indicaram que ambos os óleos apresentam estabilidade térmica até $250^{\circ} \mathrm{C}$, composição química semelhante e alto teor de ácidos graxos insaturados (71,80 e 73,00\%). Pela composição de ácidos graxos também foi possível determinar a provável composição em triacilgliceróis dos óleos. Os resultados mostraram que os óleos apresentam características semelhantes a óleos comestíveis de boa qualidade.

Palavras-chave: limão rosa, limão siciliano, óleo de sementes, caracterização.
\end{abstract}

\section{SUMMARY}

CHARACTERIZATION OF RANGPUR LIME (Citrus limonia Osbeck) AND "SICILIAN" LEMON (Citrus limon) SEED OILS, AN AGROINDUSTRIAL WASTE. The purpose of this study was to characterize the oil extracted from rangpur lime and "Sicilian" lemon seeds. Iodine, peroxide values, as well as free fatty acid percent (FFA\%) expressed as oleic acid were accomplished. The thermal gravimetric analysis, TG; differential thermal gravimetric, DTG; differential scanning calorimetry analysis, DSC; infrared and ultraviolet spectroscopic and gas chromatographic analysis were also determined. In the rangpur lime seed oil, the following fatty acids, as methyl esters were identified: caprilic $(0,90 \%)$, palmitic $(21,40 \%)$, stearic $(2,60 \%)$, oleic $(21,20 \%)$, linoleic $(43,00 \%)$, linolenic $(7,60 \%)$ and araquidic $(0,20 \%)$ and in the Sicilian lemon seed oil: caprilic $(1,00 \%)$, myristic $(0,10 \%)$, palmitic $(19,60 \%)$, stearic $(3,00 \%)$, oleic $(28,60 \%)$, linoleic $(34,40 \%)$, linolenic $(10,00 \%)$ and araquidic $(0,20 \%)$. The results indicate that both oils present thermal stability until $250^{\circ} \mathrm{C}$, as well as analogous chemical composition and high contents of unsaturated fatty acids (UFA, $71,80$ and $73,00 \%)$. With the fatty acid composition, it was possible to determine the triacylglycerol composition of both oils. The results indicated that the oils show characteristics analogous to the edible oils with good quality.

Keywords: Rangpur lime, Sicilian lemon, seed oils, characterization.

\section{1 - INTRODUÇÃO}

A tendência mundial ao consumo de produtos naturais, como sucos de frutas cítricas, tem contribuído para estimular o aumento da produção de citros no Brasil, que levou o país à liderança mundial na exportação de suco de laranja concentrado [5].

Além da laranja, outros citros são utilizados para a fabricação de sucos naturais e concentrados como limão rosa (Citrus limonia) e o limão siciliano (Citrus limon). O limão rosa, conhecido como limão cravo, é extensamente cultivado em pomares e viveiros, pois induz a maturação precoce das

\footnotetext{
${ }^{1}$ Recebido para publicação em 11/06/2004. Aceito para publicação em 28/07/2005 (001361).

${ }^{2}$ Mestrando do Curso de Pós-graduação em Ciência e Tecnologia de Alimentos - Universidade Estadual de Ponta Grossa - PR.

${ }^{3}$ Centro Federal de Educação Tecnológica - CEFET - Ponta Grossa - PR.

${ }^{4}$ Departamento de Engenharia de Alimentos - Universidade Estadual de Ponta Grossa - PR.

${ }^{5}$ Departamento de Química - Universidade Estadual de Ponta Grossa - Av.: Gal. Carlos Cavalcanti, 4748 - Campus Uvaranas - Ponta Grossa - PR -84030-900.E-mail:pibc@uepg.br.

* A quem a correspondência deve ser enviada.
}

frutas, proporcionando melhores preços no início da safra, além de ser utilizado como porta-enxerto. O limão siciliano é utilizado industrialmente como flavorizante em alimentos, devido ao óleo essencial presente em sua casca. A industrialização de citros produz grandes quantidades de resíduos como cascas e sementes, em parte utilizados em ração animal ou fertilizantes, porém o custo de secagem e transporte é um fator economicamente limitante. A porção descartada no meio ambiente, representa um problema ambiental crescente $[9,11]$.

Grande parte do resíduo sólido das sementes de citros é uma fonte inexplorada de óleo que pode alcançar $55 \%$ de rendimento\% $[5,6,8,9,12,14]$. Estes óleos podem ser aproveitados pela indústria alimentícia, farmacêutica e de cosméticos.

AJEWOLE \& ADEYEYE [1] extraíram óleos de sementes de citros ( 24,3 a $41,1 \%$ de rendimento), com propriedades físico-químicas e composição de ácidos graxos comparáveis aos óleos vegetais de boa qualidade, podendo ser utilizados para o consumo humano. O óleo de sementes de citros é composto basicamente por triacilgliceróis e, em menor quantidade, por ácidos graxos livres, hidrocarbonetos, esteróis e matéria não-gordurosa como limonina 
e naringina [6, 9]. Estes óleos podem apresentar compostos com atividade biológica, como limonóides e seus glicosídeos, que causaram inibição de tumor cancerígeno induzido em ratos, camundongos e hamsters [15]. Outros estudos indicaram atividade antibiótica do óleo extraído de sementes de limão siciliano, como a inibição de $60 \%$ do crescimento do fungo Leucoagaricus gongylophorus, simbionte das formigas cortadeiras [5].

A finalidade deste estudo foi caracterizar os óleos extraídos das sementes de limão rosa e siciliano por técnicas cromatográficas, espectroscópicas e termoanalíticas, visando seu aproveitamento tecnológico.

\section{2 - MATERIAL E MÉTODOS}

Frutos maduros dos limões foram adquiridos num supermercado do município de Ponta Grossa/PR. Os frutos foram cortados em pedaços pequenos e as sementes foram separadas do bagaço manualmente, lavadas e secas em estufa à temperatura de $50-55^{\circ} \mathrm{C}$ durante 72 horas até peso constante. A seguir foram trituradas e submetidas à extração contínua em extrator de Soxhlet por 8 horas em hexano, como descrito nas Normas Analíticas do Instituto Adolfo Lutz [16]. O solvente foi removido em evaporador rotativo obtendo-se óleos de cor amarelada que foram pesados e o seu percentual calculado sobre o peso da amostra seca [10].

As sementes secas e trituradas foram submetidas à análise térmica para a determinação do teor de umidade. Nos óleos extraídos, utilizando metodologia oficial da AOCS [17], foram determinados os índices de iodo (AOCS-Cd 1b-87), peróxidos (AOCS-Cd 8-53) e porcentagem de ácidos graxos livres (AOCS-Ca 5a-40) expressa em\% de ácido oléico.

As curvas termoanalíticas foram obtidas em módulo simultâneo TG/DSC/DTG em equipamento TA - Instruments, modelo 2960, numa faixa de temperatura de 0 a $350^{\circ} \mathrm{C}$ para a análise das sementes secas e de 0 a $500^{\circ} \mathrm{C}$ para a análise do óleo, com razão de aquecimento de $20^{\circ} \mathrm{C} \cdot \mathrm{min}^{-1}$ em atmosfera de ar e vazão de $50 \mathrm{~mL} \cdot \mathrm{min}^{-1}$ em cadinho de alumina e massa da amostra de aproximadamente 10 a $20 \mathrm{mg}[20]$.

Os espectros de infravermelho dos óleos foram obtidos em espectrofotômetro Shimadzu modelo FTIR 8400, em pastilha de $\mathrm{KBr}$ ( $100 \mathrm{mg}$ ) e $5 \mu \mathrm{L}$ de óleo [19]. Os espectros de ultravioleta dos óleos foram obtidos em espectrofotômetro Shimadzu modelo MultiSpec 1501 em solução 2.10-4 M (em ácido oléico) em isopropanol, de acordo com metodologia da IUPAC [18], método II.D.23.

Os ésteres metílicos dos ácidos graxos presentes nos óleos foram obtidos segundo o método de HARTMAN \& LAGO [7] e as análises cromatográficas foram realizadas segundo o método oficial de FIRESTONE [3], utilizandose um Cromatógrafo gasoso CG-Master equipado com coluna capilar (CG-745; $30 \mathrm{~m} ; 0,53 \mathrm{~mm}$ de espessura; filme de polietilenoglicol, $1 \mu \mathrm{m}$ ), detector de ionização de chama e nitrogênio como gás de arraste (30 mL.min $\left.{ }^{-1}\right)$.
As temperaturas utilizadas no injetor e no detector foram 220 e $250^{\circ} \mathrm{C}$, respectivamente. A programação de temperatura da coluna foi iniciada em $100^{\circ} \mathrm{C}$, aquecida a $5^{\circ} \mathrm{C}$. $\mathrm{min}^{-1}$ até $220^{\circ} \mathrm{C}$ e mantida em isoterma a $220^{\circ} \mathrm{C}$ durante 25 minutos. A solução de referência foi preparada com 16 ésteres metílicos. $1 \mu \mathrm{L}$ da solução da amostra esterificada foi injetado no cromatógrafo gasoso em duplicata e os ésteres metílicos foram identificados por comparação dos tempos de retenção com os da solução de referência. A análise quantitativa foi realizada por normalização interna, assumindo que todos os componentes da amostra estão representados no cromatograma obtido, de tal forma que as áreas de todos os picos representam 100\% com eluição total.

A composição provável de triacilgliceróis dos óleos foi determinada pelo uso de um programa computacional desenvolvido por ANTONIOSI FILHO et al. [2], que leva em consideração a composição em ácidos graxos da amostra.

\section{3 - RESULTADOS E DISCUSSÃo}

Os perfis cromatográficos dos ácidos graxos, na forma de ésteres metílicos, das amostras dos óleos extraídos das sementes de limão rosa e siciliano estão apresentados na Tabela 1 .

Os teores de umidade das sementes frescas de limão rosa, 48,0\%, e limão siciliano, 48,30\% foram próximos aos encontrados por KOBORI \& JORGE [9] para a semente de goiaba, $43,30 \%$.

Os teores de lipídeos obtidos para as sementes de limões rosa e siciliano, 32,00 e 38,30\% respectivamente, situam-se entre os valores encontrados por AJEWOLE \& ADEYEYE [1] para as sementes de Citrus reticulata (tangerina), 24,30\%, e Citrus aurantifolia (lima), 41,10\%, e próximos ao teor de lipídeos de sementes de girassol obtido por STAHL et al. [14], 31,30\%. Porém foi superior ao encontrado por FERNANDES et al. [5] em limão siciliano, 24,60\%, e tangerina 28,30\%. KOBORI \& JORGE [9] encontraram 8,60 e $12,30 \%$ de teor de lipídeos em sementes de tomate e goiaba, respectivamente.

Os índices de iodo dos óleos extraídos das sementes de limão rosa e siciliano 104,16 e 105,02, respectivamente, indicaram que ambos os óleos apresentam alto grau de insaturação, 71,80 e 73,00\% de ácidos graxos insaturados, respectivamente.

O teor de ácidos graxos livres, menores que 1,0\%, e o teor de peróxidos de 1,94 e 1,90 mEq. $\mathrm{kg}^{-1}$ para os óleos de semente de limão rosa e siciliano, respectivamente, atendem às exigências legais para o óleo refinado de soja Tipo 1 (menor ou igual a 2,50 mEq. $\mathrm{kg}^{-1}$ ), indicando tratar-se de óleos de boa qualidade [4].

O teor de ácido palmítico obtido no óleo do limão siciliano, 19,60\%, é inferior ao obtido por FERNANDES et al. [5], 29,80 e 29,30\%, para óleos extraídos com hexano e $\mathrm{CO}_{2}$ supercrítico, respectivamente. Os teores de ácido esteárico e linolênico obtidos da amostra de 
TABELA 1 - Características físico-químicas e composição em ácidos graxos identificados como ésteres metílicos dos triacilgliceróis dos óleos extraídos com hexano das sementes de limão rosa e limão siciliano

\begin{tabular}{|c|c|c|}
\hline & Limão rosa & Limão siciliano \\
\hline Umidade das sementes frescas & 48,00 & 48,30 \\
\hline Umidade das sementes secas & 5,80 & 3,60 \\
\hline AGL (\% em ácido oléico) & 0,30 & 0,27 \\
\hline Índice de iodo $\left(\mathrm{g} \mathrm{I}_{2} / 100 \mathrm{~g}\right)$ & 104,16 & 105,02 \\
\hline Teor de peróxidos (mEq/kg) & 1,94 & 1,90 \\
\hline Lipídios totais (\% peso seco) & 32,00 & 38,30 \\
\hline Grau de insaturação (\%) & 71,80 & 73,00 \\
\hline
\end{tabular}

\begin{tabular}{|c|c|c|c|c|}
\hline \multicolumn{5}{|c|}{ Composição em ácidos graxos ${ }^{a}$} \\
\hline \multirow{2}{*}{$\begin{array}{l}\text { Símbolo } \\
\mathrm{Ci}\end{array}$} & \multicolumn{2}{|c|}{ Ácido graxo } & \multicolumn{2}{|c|}{$\%$ mássica } \\
\hline & C 8:0 & caprílico & 0,90 & 1,00 \\
\hline M & C 14:0 & mirístico & n.d. & 0,10 \\
\hline$P$ & C 16:0 & palmítico & 21,40 & 19,60 \\
\hline S & C 18:0 & esteárico & 2,60 & 3,00 \\
\hline $\mathrm{O}$ & C $18: 1$ & oléico & 21,20 & 28,60 \\
\hline $\mathrm{Li}$ & C $18: 2$ & linoléico & 43,00 & 34,40 \\
\hline Lê & C $18: 3$ & linolênico & 7,60 & 10,00 \\
\hline \multirow[t]{2}{*}{ A } & C 20:0 & araquídico & 0,20 & 0,20 \\
\hline & \multicolumn{2}{|c|}{ Desconhecidos* } & 3,10 & 3,10 \\
\hline
\end{tabular}

a Os ácidos: C 6:0 capróico; C 7:0 enântico; C 9:0 pelargônico; C 10:0 cáprico; C 11:0 undecílico; C 12:0 láurico; C 13:0 tridecílico e C 22:0 behênico estão ausentes nos óleos estudados;

${ }^{\mathrm{b}} \mathrm{Em} \mathrm{C} \boldsymbol{x}: \boldsymbol{y}, \boldsymbol{x}=$ número de carbonos e $\boldsymbol{y}=$ número de duplas ligações

n.d. $=$ não detectado

* = não identificados e com tempos de retenção situados entre os dos ácidos palmítico e esteárico [C 18:0 < $\mathrm{t}_{\mathrm{r}}>\mathrm{C}$ 16:0]

limão siciliano, 3,00 e 10,00\%, respectivamente, também foram menores que os obtidos por FERNANDES et al. [5] 5,00 e 5,80\% de ácido esteárico para óleos extraídos com hexano e $\mathrm{CO}_{2}$ supercrítico, respectivamente, e 38,70 e 38,10\% de ácido linolênico para óleos extraídos com hexano e $\mathrm{CO}_{2}$ supercrítico, respectivamente. Já os teores de ácido oléico e linoléico, 28,60 e 34,40\%, respectivamente, obtidos para o óleo de limão siciliano, foram maiores que os obtidos por FERNANDES et al. [5] 2,40 e 1,90\% de ácido oléico para óleos extraídos com hexano e $\mathrm{CO}_{2}$ supercrítico, respectivamente, e 24, 10 e $23,90 \%$ de ácido linoléico para óleos extraídos com hexano e $\mathrm{CO}_{2}$ supercrítico, respectivamente.

A Tabela 2 apresenta a provável composição em triacilgliceróis dos óleos extraídos usando o programa computacional desenvolvido por ANTONIOSI FILHO et al. [2]. Para a determinação desta composição, dois aspectos são considerados. Em primeiro lugar, o principal triacilglicerol representa o componente de maior concentração no isômero com $x$ carbonos e $y$ duplas ligações. Grupos com concentração total de triacilgliceróis menor que $0,5 \%$ foram ignorados, por esta razão os ácidos graxos mirístico e araquídico que aparecem na Tabela 1, não aparecem explicitamente na Tabela 2.

Nas Figuras 1 e 2 estão apresentadas as curvas TG, DSC e DTG para as sementes desidratadas de limão rosa e limão siciliano indicando que o teor de umidade desses óleos é de 5,80 e 3,60\%, respectivamente. Esses valores estão dento da faixa recomendada por SOUZA JÚNIOR
TABELA 2 - Provável composição em triacilgliceróis dos óleos de semente de limão rosa e limão siciliano

\begin{tabular}{lccc}
\hline \multirow{2}{*}{ Triacilglicerol principal } & \multicolumn{2}{c}{$\begin{array}{c}\text { Limão rosa } \\
\text { \% mássica }\end{array}$} \\
\hline CiPLi & Grupo & 0,56 & - \\
CiOLi & $42: 2^{a}$ & 0,57 & 0,7 \\
CiLiLi & $44: 3$ & 0,68 & 0,6 \\
PPO & $44: 4$ & 3,32 & 3,78 \\
PPLi & $50: 1$ & 6,73 & 4,57 \\
PPLe & $50: 2$ & 1,19 & 1,39 \\
PSO & $50: 3$ & 0,81 & 1,16 \\
POO & $52: 1$ & 4,92 & 6,89 \\
POLi & $52: 2$ & 13,62 & 13,65 \\
PLiLi & $52: 3$ & 15,88 & 11,81 \\
PLiLe & $52: 4$ & 4,78 & 4,63 \\
PLeLe & $52: 5$ & - & 0,67 \\
SOO & $52: 6$ & 0,62 & 1,04 \\
SOLi & $54: 2$ & 2,74 & - \\
OOO & $54: 3$ & - & 4,76 \\
OOLi & $54: 3$ & 8,53 & 11,47 \\
OLiLi & $54: 4$ & 15,14 & 15,14 \\
OLiLe & $54: 5$ & - & 11,52 \\
LiLiLi & $54: 6$ & 13,84 & - \\
LiLiLe & $54: 6$ & 5,22 & 5,04 \\
LiLeLe & $54: 7$ & 0,85 & 1,18 \\
\hline
\end{tabular}

${ }^{\mathrm{a} E m ~} \boldsymbol{X}: Y, \boldsymbol{X}=$ número de carbonos (exceto carbonos do glicerol), $\boldsymbol{Y}=$ número de duplas ligações

[13], menor que $10,00 \%$ de umidade, para que haja uma extração eficiente de óleo de sementes desidratadas.

Nas Figuras 3 e 4 estão apresentadas as curvas TG, DSC e DTG mostrando o início da decomposição térmica dos óleos extraídos das sementes de limão rosa e limão 


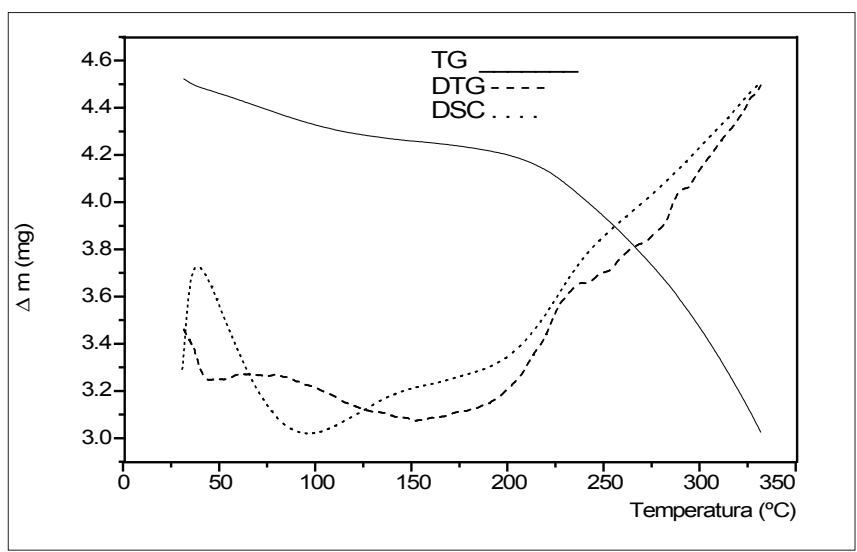

FIGURA 1 - Curvas TG, DTG e DSC das sementes secas de limão rosa em atmosfera de ar sintético

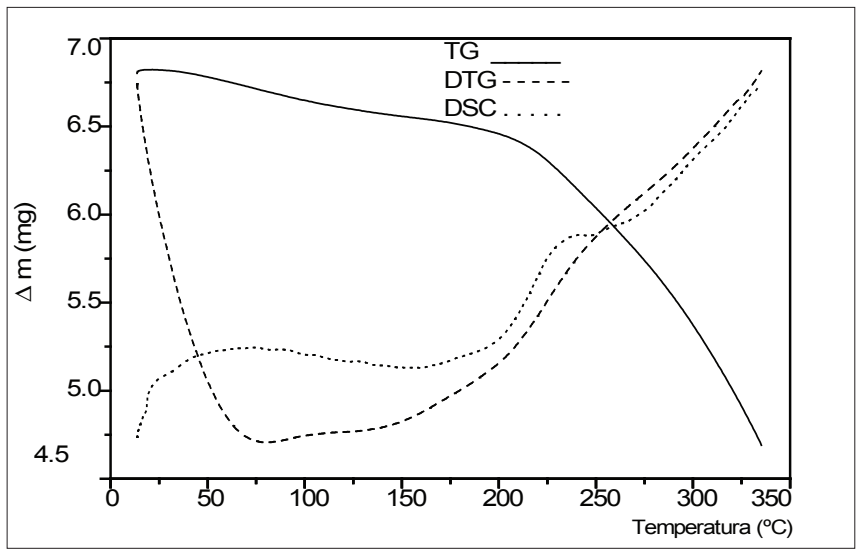

FIGURA 2 - Curvas TG, DTG e DSC das sementes secas de limão siciliano em atmosfera de ar sintético

siciliano em torno de $250^{\circ} \mathrm{C}$ e término com a conseqüente carbonização em $480^{\circ} \mathrm{C}$. As curvas mostram duas etapas bem definidas de perda de massa para o óleo do limão rosa: dois picos exotérmicos, o primeiro em $390,5^{\circ} \mathrm{C}$ e o segundo em $439,3^{\circ} \mathrm{C}$. As curvas também mostram duas etapas bem definidas de perda de massa para o óleo do limão siciliano: dois picos exotérmicos, o primeiro em $396^{\circ} \mathrm{C}$ e o segundo em $428^{\circ} \mathrm{C}$.

As curvas TG/DSC/DTG das Figuras 3 e 4 mostram que os óleos de sementes dos limões rosa e siciliano apresentam estabilidade térmica até $250^{\circ} \mathrm{C}$, temperatura maior que a usualmente utilizada para fritura de alimentos.

A Figura 5 mostra o espectro de absorção no ultravioleta dos óleos extraídos das sementes de limão rosa ( $\mathrm{A}=$ $0,44 \varepsilon=2.200)$ e limão siciliano $(\mathrm{A}=0,60 \varepsilon=3.000)$. Os espectros foram sobrepostos para facilitar a visualização das absorções máximas em $\lambda=225 \mathrm{~nm}$, devido ao alto grau de insaturação destes óleos, $71,80 \%$ e $73,00 \%$, respectivamente. Os óleos de espécies vegetais semelhantes mostram composição química análoga e praticamente o mesmo espectro.

A Figura 6 mostra o espectro de absorção no infravermelho dos óleos extraídos das sementes de limão rosa e limão siciliano.

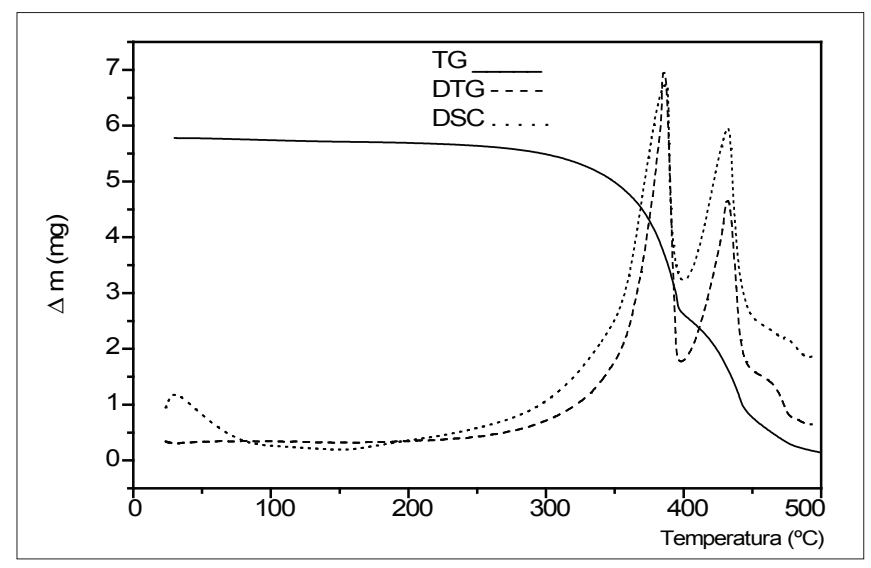

FIGURA 3 - Curvas TG, DTG e DSC do óleo das sementes de limão rosa em atmosfera de ar sintético

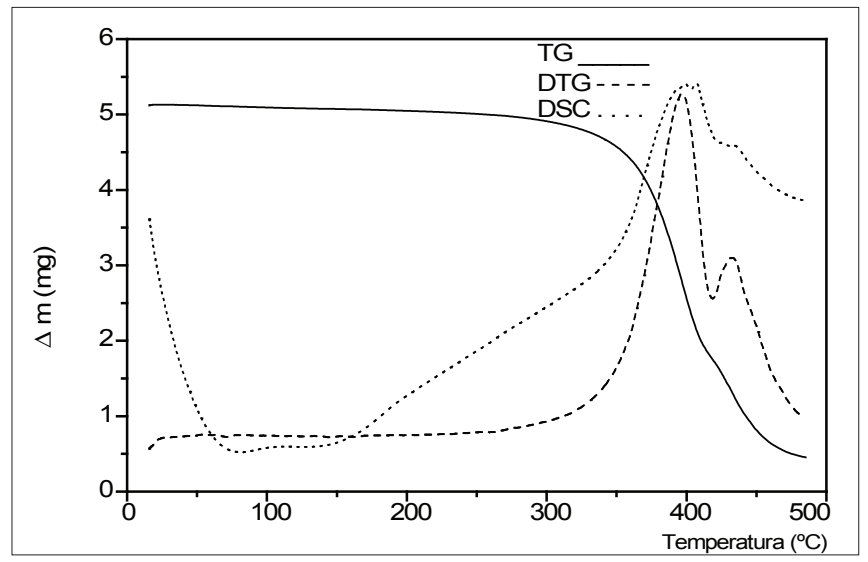

FIGURA 4 - Curvas TG, DTG e DSC do óleo das sementes de limão siciliano em atmosfera de ar sintético

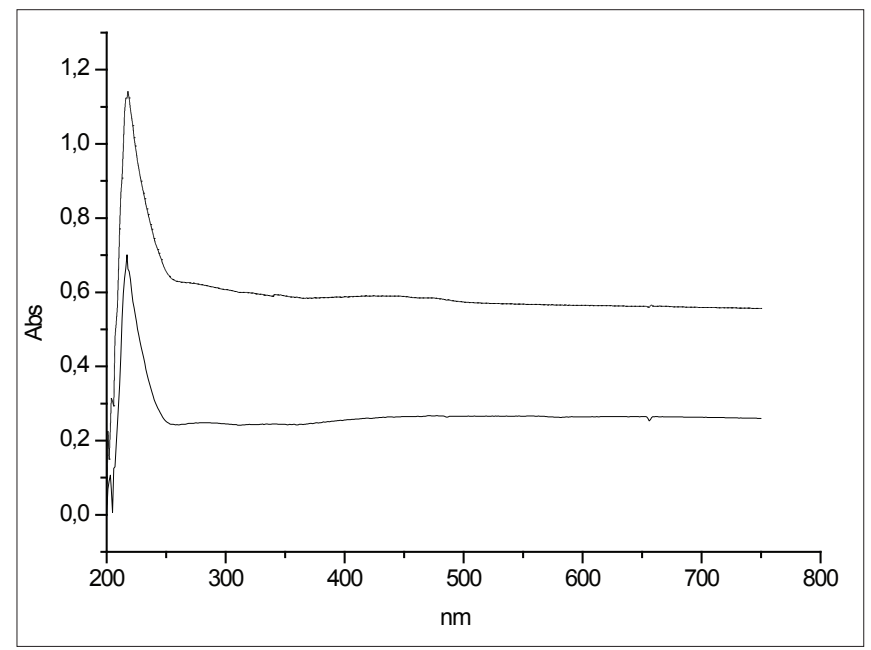

FIGURA 5 - Espectro de absorção no ultravioleta dos óleos das sementes de limão rosa e limão siciliano (Limão rosa: [...], Limão siciliano: [-])

Os espectros foram sobrepostos para facilitar a visualização das absorções das ligações $\mathrm{C}-\mathrm{H}$ do esqueleto hidrocarbônico em 2924, 2855 e $1458 \mathrm{~cm}^{-1}$; uma banda larga entre $3600-3200 \mathrm{~cm}^{-1}$ das hidroxilas das carboxilas dos ácidos graxos livres presentes na amostra em liga- 


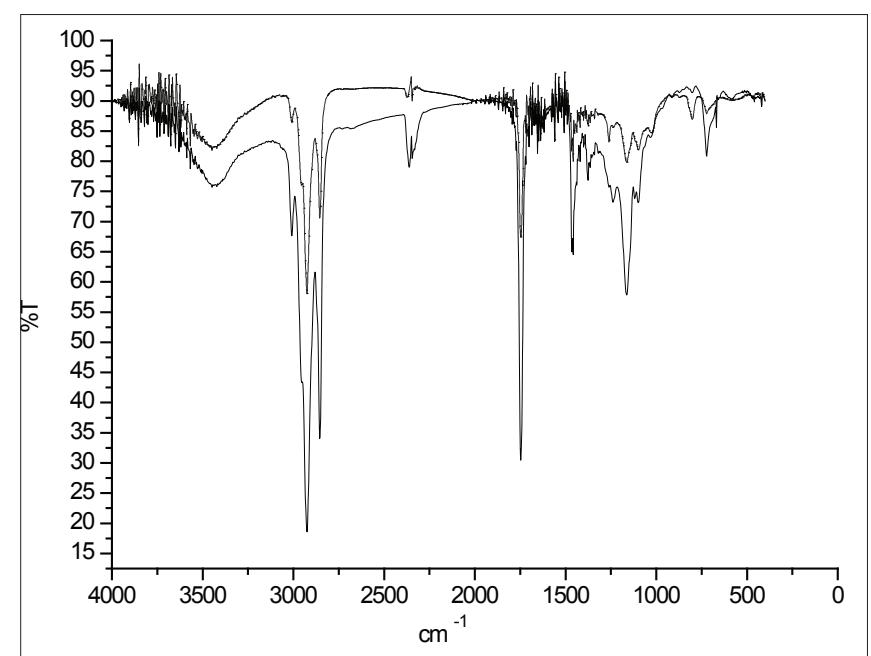

FIGURA 6 - Espectro de absorção no infravermelho dos óleos das sementes de limão rosa e limão siciliano (Limão rosa: [...], Limão siciliano: $[-])$

ção de hidrogênio; absorção da ligação H-C das duplas ligações presentes nos ácidos graxos insaturados em $3009 \mathrm{~cm}^{-1}$ e $1560 \mathrm{~cm}^{-1}$; absorção da carbonila de ésteres em 1746 cm$^{-1}$ e absorção das ligações C-OH em 1163 e $1099 \mathrm{~cm}^{-1}$. Os óleos de espécies vegetais semelhantes mostram composição química análoga e praticamente o mesmo espectro.

\section{4 - CONCLUSÕES}

Os resultados de teores de ácidos graxos indicaram que ambos os óleos apresentam composição química semelhante, alto grau de insaturação, 71,80 e 73,00\%, para o limão rosa e siciliano, respectivamente e, portanto, são adequados para consumo humano.

As duplas ligações isoladas $[\mathrm{C}=\mathrm{C}]$ presentes nas estruturas de aproximadamente $72 \%( \pm 1)$ dos ácidos graxos desses óleos e responsáveis pelo grau de insaturação não são adequadas à indústria de tintas e vernizes, pois tornam os óleos não secantes.

As análises físico-químicas, espectroscópicas, termoanalíticas e cromatográficas dos óleos das sementes destes citros indicaram propriedades comparáveis a óleos vegetais de boa qualidade, podendo ser utilizados na indústria como fonte alternativa de alimentos.

\section{5 - REFERÊNCIAS BIBLIOGRÁFICAS}

[1] AJEWOLE, K.; ADEYEYE, A. Characterization of Nigerian citrus seed oils. Food Chemistry, v. 47, p. 77-78, Sep. 1993.

[2] ANTONIOSI FILHO, N.R., MENDES, O.L., LANÇAS, F.M. Computer prediction of triacylglycerol composition of vegetable oils by HRGC. Chromatographia, v. 40, p. 557-562, 1995.

[3] FIRESTONE, D. Official Methods and Recommended Practices of the American Oil Chemists Society. $4^{\text {th }}$ ed. Champaign: AOCS, 1990. v. $1 / 2$.
[4] CELLA, R.C.F.; REGITANO-D'ARCE, M.A.B.; SPOTO, M.H.F. Comportamento do óleo de soja refinado utilizado em fritura por imersão com alimentos de origem vegetal. Ciência e Tecnologia de Alimentos, Campinas, v. 22, p. 111-116, maio/ago. 2002.

[5] FERNANDES, J.B.; et al. Extrações de óleos de sementes de citros e suas atividades sobre a formiga cortadeira Atta sexdens e seu fungo simbionte. Química Nova, v. 25, n. 6B, p. 1091-1095, mar. 2002.

[6] GIANNUZZO, A.N.; et al. Extracción de Naringina de Citrus paradisi L. Estudio comparativo y optimización de técnicas extractivas. Ciência e Tecnologia de Alimentos, v. 20, n. 2, maio/ago, 2000.

[7] HARTMAN, L.; LAGO, R.C. Rapid preparation of fatty acid methyl esthers. Laboratory Practice, v. 22, p. 475-476, 1973.

[8] JUAN-QING, C.; ZHENG-JU, Z.; FAN, P. The study on the constituents of leaf essential oils in Citrus Limonia Osbeck. Acta Botanica Sinica, v. 30, n. 2, p. 226-228, 1988.

[9] KOBORI, C.N.; JORGE, N. Caracterização dos óleos extraídos das sementes de laranja e maracujá como aproveitamento de resíduos industriais. In: Encontro Regional Sul de Ciência e Tecnologia de Alimentos, 8, 2003, Curitiba: PUC, set. 2003.

[10] MORETTO, E.; FETT, R.; GONZAGA, L. V. Introdução à Ciência de Alimentos. Florianópolis: UFSC, 255 p., 2002.

[11] OJEDA DE RODRIGUEZ, G. et al. Composition of Venezuelan lemon essential oil Citrus limon (L.) Burm. F., Ver. Fac. Agron. (LUZ), v. 15, p. 343-349, maio, 1998.

[12] SGUISSARDI, J.C.Z.; PAROUL, N.; CICHOSKI, A. Análise de voláteis e extratos residuais da hidrodestilação da casca de laranja (Citrus sinensis). In: Encontro Regional Sul de Ciência e Tecnologia de Alimentos, 8, 2003, Curitiba: PUC, set. 2003.

[13] SOUZA JÚNIOR, A.J. Considerações sobre o aproveitamento das sementes. Boletim do Instituto de Tecnologia de Alimentos, v. 39, p. 3-24, 1974.

[14] STAHL, E.; SCHUTZ, E.; MANGOLD, H.K. Extraction of seed oils with liquid and supercritical carbon dioxide. Journal Agricultural Food Chemistry, v. 28, p. 1153-1157, 1980.

[15] SCHMANDKE, H. Citrus limonoids - bitter principle and anticarcinogenic activity. Ernaehrungs-Umschau, v. 50, n. 11, p. 432-435, 2003.

[16] INSTITUTO ADOLFO LUTZ; Normas Analíticas do Instituto Adolfo Lutz. Métodos químicos e físicos para análise de alimentos. $3^{\mathrm{a}}$ ed., São Paulo, vol. 1, p. 25, 1985.

[17] American Oil Chemistry Society. Official methods and recommended practices, $4^{\text {th }}$ ed., Champaign, 1990. 2 v.

[18] International Union of Pure and Applied Chemistry. Standard methods for the analysis of oils, fats and derivatives, $6^{\text {th }}$ ed., 1979.

[19] SILVERTEIN, R.M; BASSLER, G.C; MORRILL, T.C. Identificação Espectrométrica de Compostos Orgânicos. $5^{\mathrm{a}}$ ed., Guanabara Koogan, R. Janeiro, 1991,387 p.

[20] RICHARDSON, M.J; Standardization and Quality Assurance. Journal of Thermal Analysis and Calorimetry, v. 56, p. 1401-1404, 1999. 